\title{
Treating Tropical Pyomyositis (Myositis Tropicans) Using Primary Closure and Vacuum Drainage
}

\author{
Joseph Yorke1,2, Pius Agbenorku'2,3*, Joseph Akpaloo',3, Charles Appiah'2, \\ Papa Kwesi Sansomir Fiifi-Yankson'2, Michael Adinku², \\ Ewura Adjoa Ahenfoa Ben-Crentsil'2, Dennis Afful-Yorke ${ }^{4}$ \\ ${ }^{1}$ Department of Surgery, School of Medical Sciences, College of Health Sciences, Kwame Nkrumah University of \\ Science and Technology, Kumasi, Ghana \\ ${ }^{2}$ Directorate of Surgery, Komfo Anokye Teaching Hospital, Kumasi, Ghana \\ ${ }^{3}$ Reconstructive Plastic Surgery \& Burns Unit, Department of Surgery, School of Medical Sciences, College of \\ Health Sciences, Kwame Nkrumah University of Science and Technology, Kumasi, Ghana \\ ${ }^{4}$ School of Medical Sciences, College of Health Sciences, Kwame Nkrumah University of Science and Technology, \\ Kumasi, Ghana \\ Email: *pimagben@yahoo.com
}

Received 23 May 2014; revised 20 June 2014; accepted 15 July 2014

Copyright (C) 2014 by authors and Scientific Research Publishing Inc.

This work is licensed under the Creative Commons Attribution International License (CC BY).

http://creativecommons.org/licenses/by/4.0/

(c) (i) Open Access

\section{Abstract}

Introduction: Tropical pyomyositis refers to bacterial infection that affects skeletal muscles causing single or multiple abscesses filled with pus. Aim: The study seeks to find out the effectiveness in the use of primary closure and vacuum drainage in the treatment of pyomyositis. Materials and Methods: The study was conducted between March 1, 2007 and February 28, 2014 at the Komfo Anokye Teaching Hospital, Kumasi, Ghana on patients with pyomyositis. Results: Seventy-seven patients comprising $58(75.32 \%)$ males and $19(24.68 \%)$ females were included in the study with their ages ranging from 15 to 68 years. There was improvement in patient's healing outcome. Conclusion: Primary wound closure and vacuum drainage provides patients with much satisfaction and better outcome as well and it is also effective.

\section{Keywords}

Pyomyositis, Primary Closure, Negative Wound Pressure Therapy (NWPT), Satisfaction, Cost, Outcome

\footnotetext{
${ }^{*}$ Corresponding author.
}

How to cite this paper: Yorke, J., Agbenorku, P., Akpaloo, J., Appiah, C., Fiifi-Yankson, P.K.S., Adinku, M., Ben-Crentsil, E.A.A. and Afful-Yorke, D. (2014) Treating Tropical Pyomyositis (Myositis Tropicans) Using Primary Closure and Vacuum Drainage. Surgical Science, 5, 333-337. http://dx.doi.org/10.4236/ss.2014.58055 


\section{Introduction}

Tropical pyomyositis refers to bacterial infection that affects skeletal muscles causing single or multiple abscesses filled with pus mainly caused by Staphylococcus aureus. This condition is quite common in the tropics and referred to as myositis tropicans, tropical skeletal muscle abscess and tropical myositis; in temperate countries it is referred to as non-tropical myositis, infectious myositis or spontaneous bacterial myositis [1]-[4]. Group B, C and G Streptococcus, pneumococcus, Haemophilus spp., and Gram negative bacilli also cause the condition less commonly compared to Staphylococcus aureus occurring in 90\% in tropical and $75 \%$ in temperate region. Muscles mostly affected include abdominal, spinal and gluteal muscles, quadriceps, pectoralis major, serratus anterior, biceps, iliopsoas and gastrocnemius [5] [6]. Diagnostic tools such as magnetic resonance imaging, computed tomography and ultrasound are useful. Confirmatory diagnosis is by biopsy or aspiration of pus from affected muscle [7]. Several disadvantages such as pains experienced during regular dressing and delay healing time are associated with incision and drainage technique developed in the treatment of acute abscesses [8]. Later, a technique known as primary closure was also introduced which offers advantage such as preventing secondary infection which is associated with open drains [9]. In the current study, authors seek to find out various parameters in the incision and primary closure with vacuum drainage in the treatment of pyomyositis.

\section{Materials and Methods}

\subsection{Study Setting}

Komfo Anokye Teaching Hospital (KATH), located in Kumasi, is the second-largest hospital in Ghana and the only tertiary health institution in the middle belt of the country with currently 1000 bed capacity and an annual hospital attendance of about 679,050 patients made up of both out- and in-patients (KATH records). It is the main referral hospital for the Ashanti, Brong-Ahafo, Northern, Upper East, and Upper West regions.

\subsection{Patient Management}

The study was conducted between March 1, 2007 and February 28, 2014 at the Komfo Anokye Teaching Hospital, Kumasi, Ghana and included patients with pyomyositis who presented to the Accident and Emergency Centre and given their consent to be part of the study. Protocols followed are same as in study by Akpaloo et al., 2013 [10]. Averagely, the device was used for 10 days with length of hospitalization ranging from 5 to 9 days.

\subsection{Ethical Approval}

Ethical clearance was obtained from the Kwame Nkrumah University of Science and Technology School of Medical Sciences/Komfo Anokye Teaching Hospital Committee on Human Research, Publication and Ethics, Kumasi.

\section{Results}

Seventy-seven subjects with pyomyositis were treated using incision, primary closure and drainage under negative pressure wound therapy (NPWT). Of the 77 subjects treated, 58 (75.32\%) were males and 19 (24.68\%) were females. Ages of patients ranged from 15 to 68 years (Table 1). The length of admission ranged from 5 to 9 days.

Muscles mostly affected included abdominal, spinal and gluteal muscles, quadriceps, pectoralis major, serratus anterior, biceps, iliopsoas and gastrocnemius (Table 2).

Satisfaction rate of wound healing was assessed by patients on a scale of 1 - 5: 1: bad; 2: fair; 3: satisfactory; 4: good, and 5: excellent as shown in Table 3.

Severe wound infection was seen in 3 (3.9\%) patients hence therapy was discontinued for them. Table 4 shows the complications during the treatment.

A sample of the patients treated is shown in Figure 1.

\section{Discussion}

This method of incision, drainage, primary closure and the connection of the drainage tube to the negative pressure 


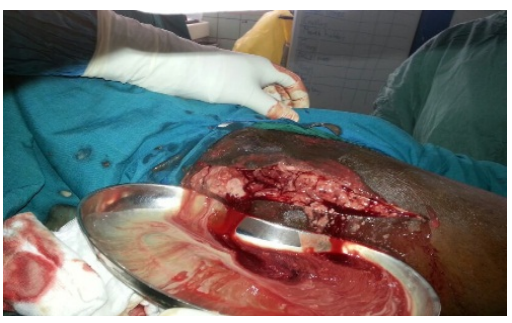

(a)

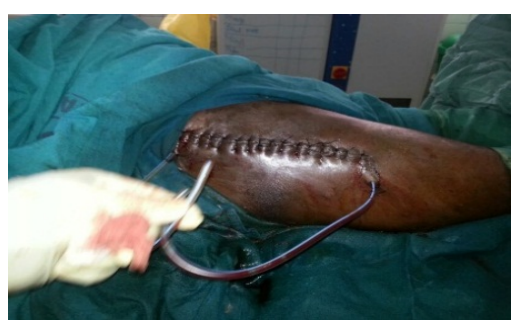

(b)

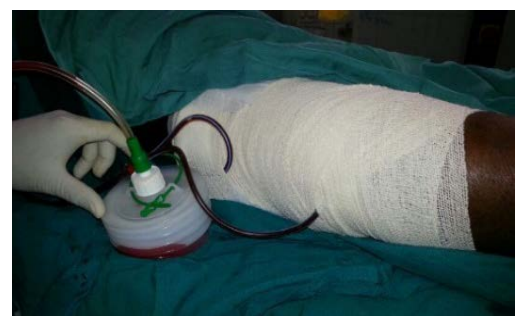

(c)

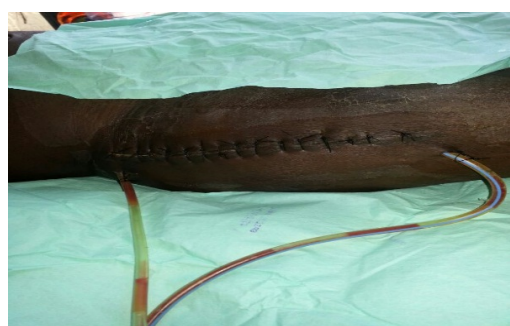

(d)

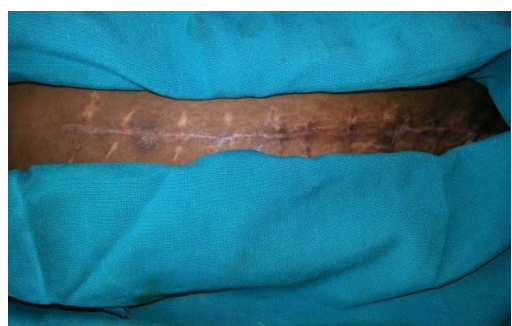

(e)

Figure 1. A patient with pyomyositis who had undergone the NPWT using the VAC device. (a) Incision and drainage of pus; (b) Drainage tubes inserted, wound closed primarily; (c) Bandaged, suction connected; (d) 5 days post OP; (e) Healed wound.

Table 1. Patients distribution in the study.

\begin{tabular}{ccccc}
\hline Age & \multicolumn{2}{c}{ Gender } & Immunocompromised & Diabetic \\
\cline { 2 - 4 } $15-25$ & Male & Female & 0 & 0 \\
$26-35$ & 5 & 3 & 1 & 1 \\
$36-45$ & 14 & 1 & 7 & 5 \\
$46-55$ & 22 & 4 & 2 & 3 \\
$56-65$ & 10 & 5 & 0 & 1 \\
$66-75$ & 4 & 5 & 0 & 1 \\
\hline
\end{tabular}

Table 2. Location of the pyomyositis.

\begin{tabular}{cccccc}
\hline $\begin{array}{c}\text { Anterior abdominal } \\
\text { wall muscle }\end{array}$ & $\begin{array}{c}\text { Quadriceps } \\
\text { muscle }\end{array}$ & Gluteal muscle & $\begin{array}{c}\text { Gastrocnemius } \\
\text { muscle }\end{array}$ & Biceps muscle & Spinal muscle \\
\hline $5(6.5 \%)$ & $38(49.3 \%)$ & $11(14.3 \%)$ & $16(20.8 \%)$ & $4(5.2 \%)$ & $2(2.6 \%)$ \\
\hline
\end{tabular}

Table 3. Satisfaction rate of wound healing.

$\begin{array}{cc}\text { Bad } & 0(0.0 \%) \\ \text { Fair } & 0(0.0 \%) \\ \text { Satisfactory } & 2(4.4 \%) \\ \text { Good } & 8(8.9 \%) \\ \text { Excellent } & 67(86.7 \%)\end{array}$

Table 4. Complications arising from the use of the NPWT device.

\begin{tabular}{cc}
\hline Severe & $3(3.9 \%)$ \\
Mild & $2(2.6 \%)$ \\
None & $72(93.5 \%)$ \\
\hline
\end{tabular}


wound therapy (NPWT) device (Variant I) provides suitable and preferable cosmetic outcome unlike unsatisfactory cosmetic outcome from the implementation of the incision and wound gauze package only (Variant II). Reduction in the number of dressing changes for Variant I benefits both the nurse who takes care of the wound and the patient with the condition in terms of decrease time as well as the pain experienced during dressing is reduced producing a better outcome for the patient. The primary closure system provides better satisfaction compared to the traditional incision and gauze package technique. Better outcome as a result of patient satisfaction provides relief to patient [11]. Also as has been reported by some authors, the primary closure system with subsequent connection to the NWPT prevents the patient from acquiring any secondary infection. Improved recovery rate implies reduction in hospitalisation and hospital cost. Administration of antibiotics only in the treatment of some abscesses is sometimes inadequate, hence the need for incision and drainage [12]. Incision and drainage often seen as an out-patient procedure is usually carried out in management of abscess or boil to release pus. This procedure may require treatment of the area with antibiotics and aseptically making an incision to allow the pus to drain through the incision. However, because of the possibility of infection, the patient should be treated with antibiotics. The use of the primary closure has been recommended to be beneficial due to its cost effectiveness and not associated with further wound complication. Thus basically this method utilizes negative pressure that promotes wound granulation similar to that obtained from the use of VAC developed by Argenta and Morykwas [13]. The primary wound closure and drainage has been reported to promote faster wound healing and reducing hospital stay. It is also reported to be a safe procedure. A study by Vosa et al. (2012) revealed the implementation of the primary wound closure system is safe and feasible and most importantly does not compromise on mortality thus, giving high survival rates for patients [12].

In all the patients in our series we used this Variant I procedure only. We did no comparison with the Variant II in our series.

\section{Conclusion}

The use of the primary wound closure and vacuum drainage in treating pyomyositis provides patients with much satisfaction, reduction in cost and hospital stay as well as more improved rate of healing and recovery than the former. It is thus more gratifying to the patient and the attendant health professional to use this method.

\section{Acknowledgements}

The authors sincerely thank the numerous nurses and doctors who helped to manage these patients.

\section{Conflict of Interest}

No conflict of interests is declared by any of the authors.

\section{References}

[1] Chacha, P.B. (1970) Muscle Abscesses in Children. Clinical Orthopaedics, 70, 174-180.

[2] Cheidozi, L.C. (1979) Pyomyositis: Review of 205 Cases in 112 Patients. The American Journal of Surgery, 137, 255-259. http://dx.doi.org/10.1016/0002-9610(79)90158-2

[3] Foster, W.D. (1965) The Bacteriology of Tropical Pyomyositis in Uganda. Journal of Hygiene, 63, 517-524. http://dx.doi.org/10.1017/S002217240004540X

[4] Ladipo, G.O. and Fakunle, Y.F. (1977) Tropical Pyomyositis in the Nigerian Savanna. Tropical and Geographical Medicine, 29, 223-228.

[5] Sarubbi, F.A., Gafford, G.D. and Bishop, D.R. (1989) Gram Negative Bacterial Pyomyositis: Unique Case and Review. Reviews of Infectious Diseases, 11, 789-792. http://dx.doi.org/10.1093/clinids/11.5.789

[6] Christin, L. and Sarosi, G.A. (1992) Pyomyositis in North America: Case Reports and Review. Clinical Infectious Diseases, 15, 668-677. http://dx.doi.org/10.1093/clind/15.4.668

[7] Chauhan, S., Jain, S., Varma, S. and Chauhan, S.S. (2004) Tropical Pyomyositis (Myositis Tropicans): Current Perspective. Postgraduate Medical Journal, 80, 267-270. http://dx.doi.org/10.1136/pgmj.2003.009274

[8] Bhishagratna, K.K. (1996) English Translation of Sushruta Samhita (ca 600 B.C.). Bose, Calcutta.

[9] Ngo, Q.D., Lam, V.W.T. and Deane, S.A. (2004) Drowning in Drainage. The Liverpool Hospital Survival Guide to Drains and Tubes. Department of Surgery, Liverpool Hospital, Liverpool. 
[10] Akpaloo, J., Yorke, J., Agbenorku, P. and Yenli, E.M.T. (2013) Managing Acute Wounds with Negative Pressure System in a Developing Country. ISRN Plastic Surgery, 2013, Article ID: 796254. http://dx.doi.org/10.5402/2013/796254

[11] Singer, A.J., Thode Jr., H.C., Chale, S., Taira, B.R. and Lee, C. (2011) Primary Closure of Cutaneous Abscesses a Systematic Review. American Journal of Emergency Medicine, 29, 361-366. http://dx.doi.org/10.1016/j.ajem.2009.10.004

[12] Vosa, R.J., Yilmaza, A., Sonkera, U., Johannes, C., Kloppenburga, K. and Geoffrey, T.L. (2012) Primary Closure Using Redon Drains vs Vacuum-Assisted Closure in Post-Sternotomy Mediastinitis. European Journal of Cardio-Thoracic Surgery, 42, e53-e57. http://dx.doi.org/10.1093/ejcts/ezs404

[13] Morykwas, M.J., Argenta, L.C., Shelton-Brown, E.I. and McGuirt, W. (1997) Vacuum-Assisted Closure: A New Method for Wound Control and Treatment: Animal Studies and Basic Foundation. Annals of Plastic Surgery, 38, 553-562. http://dx.doi.org/10.1097/00000637-199706000-00001 
Scientific Research Publishing (SCIRP) is one of the largest Open Access journal publishers. It is currently publishing more than 200 open access, online, peer-reviewed journals covering a wide range of academic disciplines. SCIRP serves the worldwide academic communities and contributes to the progress and application of science with its publication.

Other selected journals from SCIRP are listed as below. Submit your manuscript to us via either submit@scirp.org or Online Submission Portal.
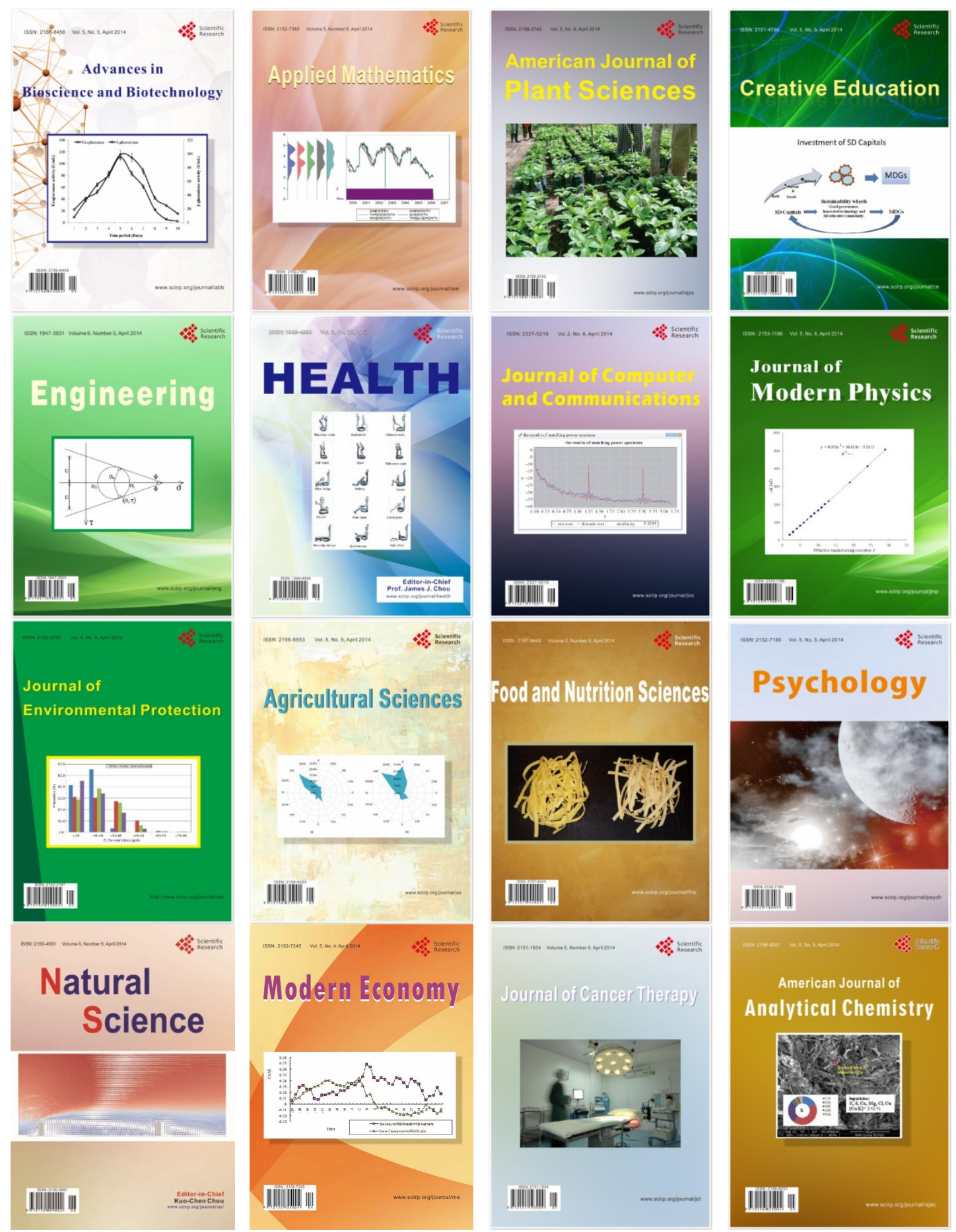